\section{Briginal alnticles.}

\section{A COMPARATIVE STUDY OF TSUTSUGAMUSHI DISEASE AND SPOTTED OR TICK FEVFR OF MONTANA.}

\author{
Captain and Assistant Surgeon, U. S. A., \\ AND \\ Charles F. CRAig, M.D.
}

First Lieutenant and Assistant Surgeon, U.S.A.

Constituting the United States Army Board for the Study of Tropical Diseases as They occur in the Philippine Islands.

I. SyNoNymy. II. InTROdUCtion. III. History of both Diseases. IV. Etiology. V. Symptoms, Tsutsugamushi, Spotted Fever. VI. Blood Examinations. VII. Mortaisty. VIII. Immunity Conffrred BY Attack. IX. Susceptibility of Animals. X. Prognosis. XI. Pathological Anatomy. XII. Diagnosis. XIII. Prophylaxis. XIV. Treatment. XV. Casfi Histories of Tsutsugamushi Disease. XVI. ConClUsion as to the Nonidentity OF the Two Diseases. XVII. Does Flood Fever Occur in the PhilipPINE ISLANDS?

\section{SYNONYMY.}

Tsutsugamushi Disease: Japanese River Fever. Flood Fever. Island Fever. Kedani Disease. Akamushi Disease. Shimamushi Disease. Yochubio. Shashitsu.

Mushi is a Japanese word meaning bug, and the compounds ending with it all relate to the etiology of the disease. Tsutsugamushi is the term employed by most Japanese people and professional men and, as it has the prestige derived from ancient and specific usage, it will be employed in this paper.

Spotted Fever of Montana: Rocky Mountain Fever. Tick Fever. Pyroplasmosis Hominis (Wilson and Chowning). Tick Fever of the Rocky Mountains. Rocky Mountain Spotted Fever.

As so-called spotted fever has been described in various parts of the Rocky Mountain region and as it has not been determined that the same disease prevails in all those parts, the term Spotted or Tick Fever of Montana will be used in this paper, the disease referred to being that occurring in western Montana, particularly in the Bitter Root Valley, in Missoula and Ravalli counties.

\section{INTRODUCTION.}

For many years past kedani or tsutsugamushi disease has been an annual subject of the most active and painstaking investigation on the part of Japanese physicians and the Japanese government.

One of the leading investigators of late years is Dr. M. Miyajima, of the Institute for Researches of Infectious Diseases, of Tokyo. Dr. Miyajima had read of the work of Wilson and Chowning, Anderson, Stiles and others, on the study of "spotted" or " tick fever" in Montana, and he had found so many points of similarity in the two diseases that he thought it quite possible that they were the same. Consequently, when he came to Manila as a representative of his government to the Philippine Islands Medical Association and we met, he was desirous that we should visit Japan at the proper season and determine, if possible, whether or not such be the case. Thanks to the representations of Dr. Miyajima and the liberal view taken of the matter by General Wood, the Acting Surgeon-General, and the War Department, we were ordered; and this report is based on the observations on tsutsugamushi disease made on that trip and the observations made by one of us (Ashburn) in 1904 and 1905 on the cases of spotted fever occurring in those years in the Bitter Root Valley in Montana.

The specific point that we were to try to determine, and which we think we have determined, was the question of the identity or nonidentity of the two diseases and most emphasis will be laid on that point in this report.

However, both diseases, being so closely restricted as to locality, are necessarily unknown to the very great majority of medical men, and a brief description of each will therefore be given and an effort made to run the descriptions parallel, so that the resemblances and differences may be brought out more strikingly. The descriptions to be given are based on personal observations of some 22 cases of spotted fever and 7 cases of tsutsugamushi disease, as well as on the writings of other men who have studied one disease or the other more carefully than we could or did.

Both diseases are still subjects of earnest and careful investigation by expert workers and it is therefore unnecessary and would be futile, in a paper of this kind, to attempt the thorough consideration of them which they deserve and will receive later.

III. HISTORY OF THE TWO DISEASES.

According to Tanaka the name tsutsugamushi has been known since the earliest historical times, while the name shashitsu occurs in old Chinese writings of more than a thousand years ago. A quotation from one such writing indicates that at that time the disease was recognized as a distinct affection and was ascribed to the bite of a mite which occurred in summer time in certain districts that had been flooded by the spring rains. The bite was described and the statement made that after three days high fever developed and a pustule appeared at the site of the injury. It was also recognized that only certain regions were infected and that the disease only appeared in persons entering them.

The disease was brought to the attention of the Western world by Palm, in 1878 and Bälz, in 1879 , and since that time it has been the subject of much painstaking work by Japanese medical men and of numerous articles in Japanese and some in foreign journals. Numerous micro-organisms, including cocci, bacilli and protozoa, have been described as the cause of the disease, and several investigators are working at the present time, each with what he thinks the causative factor. It cannot be said that any of these workers has yet established his claim.

Three hypotheses at present divide the workers and rule the work of investigation:

1. That the disease is due to a bacterium, a belief favored by the workers of the Institute for Infectious Diseases. 
2. That it is a protozoal infection. Professor Ogata is the leading exponent of this idea.

3. Tanaka thinks the disease due to a toxin contained in the body of the red mite.

Spotted fever of Montana has been recognized for only a few years, twenty-five at the most, while the literature relating to it has practically all been made since 1902. At that time Wilson and Chowning published their first account of it and their ideas as to its cause and method of transmission, in a preliminary report to the Montana State Board of Health, which appeared in the Journal of the American Medical Association. It is true that Major Wood, in 1896, and Maxey, in 1899 , had reported a similar, or the same, disease in Idaho, hut the form occurring there presents such points of difference, particularly in regard to mortality, that it is not considered in this paper. Since the work of Wilson and Chowning in 1902, the disease has each year been the subject of careful investigation and report and the prospects now are that its etiology will soon be well understood.

The total number of cases occurring each year is small and that, considered in connection with the further facts that the disease occurs in such a limited and relatively isolated region and that it has been known for so short a time, makes it remarkable that the present knowledge concerning it should be as great as it is.

\section{ETIOLOGY.}

T'sutsugamushi disease occurs along certain limited parts of the banks of a few rivers on the west coast of the main island of Nippon, being limited to Frhigo and Akita provinces. The distribution of the infected areas is irregular and, up to the present time, unexplainable. They are all subject to submergence by floods which occur in June, but not all flooded districts are infected nor does the relative location of an infected district, up or down stream, seem to influence a noninfected. The floods usually occur in June and last but a few days. Immediately after their subsidence the infective regions are not dangerous but after a few weeks or a month and synchronously with the appearance of the akamushi or red mite, they become so and any person entering them takes a considerable risk of contracting the disease. Consequently, they are then avoided by all whose poverty does not drive them there to work or gather mulberry leaves. As a general rule no right of ownership is exercised over such land and the very poor do, therefore, cultivate hemp on it in some places and in other parts visit it to gather mulberry leaves to feed silkworms. In either case they are apt to be bitten by red mites and it is customary for them to search carefully for such bites after leaving the places. However, the mites are so minute as to be very difficult of detection, and, if the bite does not cause pain, it is frequently overlooked. Not all mites are infective and many bites therefore cause no trouble. A certain proportion of them, though, do so, the point bitten becoming an eschar and later an ulcer, the neighboring lym- phatic glands becoming enlarged and painful and an attack of fever succeeding.

It is the experience of practically all who have carefully studied the disease, and they are numerous, that every case of it is preceded by the mite bite and in the great majority of cases the bite is located by an examination of the region drained by the lymphatic glands which first became enlarged and tender. So far as could be learned in Japan, Bälz's contention that such is not the case has not received support, and later investigators agree that the bite of the mite is the sole means of infection. The mite in question is the larval form of a trombidium, species unknown. The larva bears a great resemblance to that of Leptus autumnalis. It is so small as to be almost invisible to the naked eye, bright red or orange in in color, and is found on land that has been submerged by flood. Here it is best collected by tying a monkey out over night or by catching the field mice (Arvicola hatanedzumi, Sasaki) occurring in such regions. The mites collect in groups on or about the eyelids of the monkey, while they are always found attached in large numbers to the inner surfaces of the ears of the mice. Mites resembling these in size and color occur in many parts of Japan but they do not attack persons. The akamushi of other than infected regions do not transmit disease. Several supposed causative organisms have been described for this disease, the latest and probably the one calculated to excite most interest being Ogata's plasmodium. None of these alleged discoveries has been confirmed, and, judging from what we heard and what blood examinations we could make in Japan, it appears that Ogata's plasmodium does not exist. The causative organism is yet unknown.

Spotted or tick fever of Montana, as known by Wilson and Chowning, Anderson, Stiles, Ricketts and Ashburn, occurs also in very strictly limited areas, particularly in a strip of country about four to ten miles wide and fifty miles long, lying on the west side of the Bitter Root River and the eastern side of the Bitter Root Mountains and partly on the slopes of those mountains. The country in question has a considerable snowfall and the snow remains on the mountains until mid June and on the highest peaks for two or three weeks longer. The Bitter Root River is largely fed from this snow, and, as it begins to melt in March and continues to do so with increasing rapidity until most of it has disappeared, the stream is in a state of freshet during that time and does not again reach "low water" until July.

During the same period ticks, $D$. occidentalis, which before and after it are infrequently seen, appear in great numbers, particularly in the woods, thickets and uncultivated regions, and are very apt to get on any person or animal going into such parts. Likewise and, as a rule, during the same period, cases of spotted or tick fever appear, and in almost all cases there is a history of a recent visit to, or residence in, the infected district, and, in many cases, of tick bites received there. Wilson and Chowning incriminated the tick as the carrier of the disease as early as 1902 . 
From a study of all the cases occurring in 1904 and most of those occurring in 1905 Ashburn came to the conclusion that a considerable proportion of them gave neither history nor signs of tick bite and for that and other reasons which it is not necessary to detail here, agreed with Stiles that the tick was not concerned in transmitting the disease. However, the more recent and very excellent work of Ricketts and of King and their apparent success in transmitting the disease to monkeys and guinea pigs by means of the tick, seem to indicate that Wilson and Chowning were right in their belief as to the method of infection.

It mav therefore be said that the disease is introduced by the bite of $D$. occidentalis. This bite cannot always be located, possibly because the first symptoms of the disease do not indicate its location as in the tsutsugamushi disease. Certainly an ulcer and lymphadenitis do not always follow it.

Ricketts' recent observation that nymphal ticks may transmit the disease and his suggestion that larvæ $\dagger$ may do so, may account for the absence of a history of tick bite in some cases, as the lesion resulting from the bite of a larva may be insignificant and may possibly leave no trace after a few hours or a day and the larva itself may be overlooked. Most persons in the infected regions carefully watch and examine themselves for tick bites and it is improbable that the bite of the adult tick is often overlooked. In nearly all cases the disease is contracted on the hill sides or "bench," high above the river, and some persons long resident in the region say that the bottom lands and islands which are subject to submersion are free from danger.

Wilson and Chowning named the disease Piroplasmosis hominis. Later investigations, except that of Anderson, have failed to confirm their view and the disease is not now considered a piroplasmosis. The causative organism is not known.

A consideration of the etiology of the two diseases shows many points of resemblance, but also some important differences. Both occur in small and usually strictly limited areas along certain streams running through mountainous country. The country in each instance is subject to heavy snowfall in winter and the streams to spring or summer floods. Along each infected stream the dangerous spots are usually more or less uncultivated and the soil overgrown with underbrush, trees or weeds, while the immune spots are well cultivated. In each instance the disease is attributed to the bite of an Acarina and in each a supposed protozoan blood parasite has been described as the cause and has not been confirmed as such. Contagion is unknown in either disease.

The differences in the etiology of the two are equally well marked. The Acarina whose bite causes tsutsugamushi is always a six-legged, larval Trombidium, whose adult form is unknown. That causing spotted or tick fever of Montana is

t Since the above was written Ricketts (Jour. Am. Med. Asso., Oct. 12, 1907) has published reports of successful transmission of Oct. 12 , 1907) has published reports of successful transmiss always Dermacentor occidentalis and usually the adult.

Tsutsugamushi disease occurs always after floods and it is contracted on ground which has actually been submerged by the swollen river. Fields immediately adjoining the infected areas and but a few feet higher are considered safe. The Montana disease may precede the flooding of the streams or, more usually, accompanies it. It is very commonly contracted on ground which has not been submerged but is on hillsides high above the level of the river. The cases begin in March and rarely appear after the middle of July. Tsutsugamushi disease is beginning to appear at that time and continues to do so into October.

Spotted fever regions are uncultivated, either because of the elevation and roughness of the land and the difficulty of irrigating it, or because of the relative newness of the country. The tsutsugamushi infected regions are uncultivated because of their low and flat positions subjecting them to annual floods which destroy most crops and because for an immemorial period they have been recognized as dangerous.

\section{v. SYMPTOMS.}

Tsutsugamushi disease is not commonly preceded by well-marked prodromata. Occasionally there may be a few days of malaise and indisposition, but the usual history is that in from five to twelve days, rarely less than five, after the receipt of a bite from a red mite the patient has a chill; headache and fever come on and one group of lymphatic glands, usually those of one axilla or groin, is found to be enlarged, painful and tender. Examination of the region drained by these glands leads to the discovery of the lesion resulting from the bite. This lesion is small, circular and usually 2 to $4 \mathrm{~mm}$. in diameter. It is stated by some writers that in its early stages the lesion is a small vesicle. In most instances it is a black or brown area of necrosis of the derma. The dark necrotic skin is very adherent, but after a varying number of days it loosens and is cast off, leaving a circular, punched out ulcer of slightly greater diameter. The periphery of the ulcer is pinkish in color and slightly infiltrated and is not usually painful or tender. Enlargement of the lymph vessels connecting the lesion and the large and painful glands cannot be detected.

The glands, while enlarged and inflamed, do not present great swelling, are not fused together and are movable beneath the skin.

The temperature at this early stage ordinarily runs from $101^{\circ} \mathrm{F}$. to $103^{\circ} \mathrm{F}$. Tanaka states that it may reach its maximum in twenty-four hours. The pulse is from 80 to 100 and strong.

The conjunctival vessels are apt to be injected, slight cough may be present, the tongue is moist and slightly coated, the bowels constipated, and slight or moderate splenic enlargement demonstrable. The urine may contain albumin and the diazo reaction is present. The patient ordinarily feels comfortable except for headache, and the appetite may be surprisingly good.

As the disease advances the above symptoms 
become more marked. General slight enlargement of superficial glands occurs, the temperature reaches $104^{\circ} \mathrm{F}$. to $105^{\circ} \mathrm{F}$. and is continuous. The pulse weakens and quickens and may become dicrotic, the first heart sound may be impure. The presence of albumin and the diazo reaction are more marked in the urine and casts may be numerous; injection of the conjunctiva and lachrymation are more evident. Respiration is accelerated, the breath sounds are harsh, cough increases and may be harassing, though the expectoration is scanty. The entire surface of the body is apt to be hypersensitive and this causes complaint. Constipation usually persists but diarrhea and abdominal pain and tenderness occur exceptionally. The tongue becomes dry, brown in the center and glazed at the tip and edges, sordes collect and the gums may become spongy and bleed. In such cases the breath is particularly foul.

Partial deafness occurs, the patient becomes stuporous and may pass into coma before death.

At some period of the disease, usually from the fifth to the seventh day, though it may be a little earlier or later, an exanthem appears, showing first on the face and later on the chest, the forearms, the legs and the rest of the trunk. The palate and buccal surfaces also show it occasionally. The eruption consists of irregular, rather faint, dusky or pink macules or flattened papules, 2 to $5 \mathrm{~mm}$. in diameter, which may become confluent on the cheeks and give an appearance of swelling. On the relatively dark skin of a Japanese this eruption is not well shown and on other parts than the face the lesions bear a great resemblance to flea bites, with which they may be confused. They fade on pressure but at once return when it is removed. The eruption does not itch and the duration of it is usually from four to seven days, although it may be more or less. It never becomes hemorrhagic or petechial. Tanaka states that in rare instances it may become vesicular or pustular. This is probably rarer than he implies.

This period of exanthem marks the height of the disease, and as the eruption begins to fade, usually about the end of the second week, the fever remits and in a few days the temperature reaches normal, while the general condition also improves rapidly. The patient then speedily recovers, although the little ulcer resulting from the bite may be long in healing.

The above presents a recovering case of average severity. In more severe cases death may result from the ninth to the fifteenth day, or in more severe cases which recover, the fever may last longer and the symptoms be very marked.

On the other hand very light cases may show but slight and ephemeral fever, very trifling or no exanthem, and may not be bedfast. The ulcer and lymphatic enlargement are always present though, and the former may be larger than usual, as much as $1 \mathrm{~cm}$. in diameter. The duration of the disease is usually about three weeks. It may be as long as a month or as short as one week. Parotitis, melena and mania have been noted as complications, while coma, cardiac weakness and pulmonary edema may be terminal features.

Spotted or tick fever, as it occurs in the Bitter Root Valley, begins in from one to eight days after the tick bite, in cases where the history of bite is obtainable. As in tsutsugamushi disease, prodromata are unusual, the disease commonly commencing with a chill. There is not the constant signal symptom of localized lymphadenitis which enables one to find the tick bite, and when present it is usually due to pyogenic or other infection of the wound and lymphangitis may accompany it, while the margins of the lesion are more inflamed and indurated than in the other disease. In many cases no tick bite can be located. When found it does not present the constant appearance of a small round necrotic area succeeded by an ulcer as in the case of the mite bite. The temperature is not essentially different, although it does not show the constancy of type shown by that of tsutsugamushi disease; the eye symptoms, constipation and splenic enlargement may be the same.

As the disease progresses the symptoms in the main bear a great resemblance to those of tsutsugamushi disease, with the following exceptions:

$a$. The fever in the latter disease is more typically continuous; in the former more irregular.

$b$. The pulse rate in spotted fever is apt to be relatively high, as compared with the temperature; in tsutsugamushi disease it may be relatively low.

c. Most spotted fever patients are dead before the end of the second week.

$d$. The exanthem in spotted fever appears earlier, as a rule, than that of tsutsugamushi disease. It shows first on the wrists and ankles and rapidly spreads to cover the entire body. It is much more abundant and more plainly visible than that of tsutsugamushi disease, though the latter fact is doubtless related in part to the darker color of the skin in Japanese. It usually consists of macules or petechiæ, although it may resemble the rash of measles or of rötheln; but in practically all cases it soon becomes petechial or hemorrhagic and large extravasations may be produced by the confluence of neighboring hemorrhagic spots. Instead of disappearing in from four to seven days this eruption usually persists until after the patient has died or recovered, and slightly pigmented stains may mark for weeks its location on the bodies of persons recovering. Some of the points of extravasation may pass on to gangrene and sloughing, a thing unknown in tsutsugamushi disease.

e. Hemorrhagic extravasation not infrequently takes place into the scrotal tissues of male subjects of spotted fever, never in cases of the other disease.

$f$. The tongue and lips of the spotted fever case may become dry, cracked and bleeding, but the gums do not become spongy and ooze blood as they sometimes do in tsutsugamushi disease.

g. Parotitis, malena and mania have not been noted as complications. 
vi. BLOOD EXAMINATION.

No complete studies have been made, so far as we know, of the condition of the blood in tsutsugamushi disease. Tanaka states that the red cells usually run from $4,800,000$ to $5,200,000$, the leucocytes from 6,000 to 8,000 and the hemoglobin from $40 \%$ to $75 \%$.

On the other hand Dr. Miyajima informed us that the red cells fall during the course of the disease to $3,000,000$, or $4,000,000$, while the hemoglobin is reduced proportionately and that leucopenia obtains. He had not made differential counts of white cells. We were disappointed in not having apparatus for making blood counts and were forced to content ourselves with examinations of fresh and stained films. From such examinations we judge that the red cells are not deformed, that they stain normally and that the differential white cell count is not apt to be of much assistance in diagnosis. There is apparently a well marked leucopenia.

The number of cases examined by us is too small to enable us to draw any general conclusion as to the value of differential counts in the prognosis, but if they indicate anything, it is that they have such value.

It will be noticed that Case IV, discharged recovered, and Case V, suffering from a third attack and apparently not very sick, both had low polymorphonuclear and high lymphocyte counts; while cases I and II, both ending fatally, and III and VI, both serious, if not fatal, did not show either. So far, then, as a general deduction might be drawn from the consideration of differential counts on six cases, it would appear that a relative decrease of polymorphonuclear and increase of mononuclear cells, particularly of lymphocytes, constitute a favorable prognostic omen. We were unable to recognize parasites in either fresh or stained specimens of blood, except one body in a fresh film from Case VI. The body was intracellular, ameboid, unpigmented and about 1 micron in diameter. We thought it a young tertian parasite. (Malaria is common in the district.)

The following table shows the results of our differential counts. They were all made on blood drawn Aug. 2 and in each case at least 400 white cells were counted.

\begin{tabular}{|c|c|c|c|c|c|c|}
\hline & ठేं & 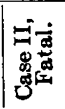 & 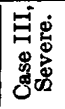 & 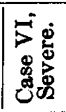 & 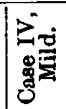 & 家 \\
\hline $\begin{array}{l}\text { Small lymphocytes, } \\
\text { Large lymphocytes, } \\
\text { Polymorphonuclears, } \\
\text { Trans. and large mono., } \\
\text { Eosinophiles, }\end{array}$ & $\begin{array}{r}7 \\
11 \\
74 \\
8\end{array}$ & $\begin{array}{r}5 \\
10 \\
80 \\
5\end{array}$ & $\begin{array}{r}8 \\
7 \\
84 \\
1\end{array}$ & $\begin{array}{r}8 \\
12 \\
77 \\
3\end{array}$ & $\begin{array}{r}18 \\
21 \\
54 \\
6 \\
1\end{array}$ & $\begin{array}{r}18 \\
27 \\
45 \\
9\end{array}$ \\
\hline
\end{tabular}

In spotted fever, as in tsutsugamushi disease the blood condition has not been sufficiently studied to permit the drawing of general deductions. Wilson and Chowning and Anderson agreed that the red cell counts were reduced about $20 \%$; the hemoglobin somewhat more; while the leucocytes were increased. In one fatal case, in a pregnant woman, Ashburn found a leucocyte count of 15,600 .
Not enough differential counts have been made to enable us to form an opinion as to their value in prognosis. Anderson reports such a count in a recovering case, the percentages being as follows: small lymphocytes, 9.9 ; large lymphocytes, 10.6 ; polymorphonuclears, 78.7; eosinophiles, 0.8.

Wilson and Chowning and Anderson described what they considered a piroplasma in the blood of spotted fever cases. Later observers have not confirmed this and we do not think that any organism can be seen.

viI. MORTALI'TY.

The mortality of tsutsugamushi disease has been variously estimated at from $15 \%$ to $70 \%$, or more. Statistics of 567 cases carefully recorded by Dr. Miyajima show an average mortality of $27 \%$.

The rate shows a steady and progressive increase from $12 \frac{1}{2} \%$ in the first decade of life to $57 \%$ in the seventh.

The mortality statistics of tick fever are not based on such a large number of cases, and it is probable that many of the cases included in Wilson and Chowning's tables, but occurring prior to 1902 , were not really spotted fever. They nevertheless figure the percentage of mortality as 75 and that is approximately correct. This disease is therefore more fatal than the other. So far as the statistics at hand give any indication, the mortality does not steadily increase with the age of the patients.

\section{IMMUNITY CONFERRED BY ATTACK.}

One attack of tsutsugamushi disease does not confer permanent immunity against another. Probably a temporary immunity is always conferred, but second and third attacks, in later years, are not rare. One of the cases seen in August was suffering from his third attack. As a rule the later attacks of the disease are milder than the first.

In tick fever second and third attacks are unknown and it seems probable that they do not occur. The number of living persons who have had the disease is so small, however, as to make generalizations on this point dangerous. Ricketts states that active immunity of at least two or three months' duration is produced in the monkey or guinea pig by an attack of the disease.

IX. SUSCEPTIBILITY OF ANIMALS.

Ogata states that tsutsugamushi disease is inoculable into kittens, apes, mice and guinea pigs. Dr. Miyajima, who has done much work on the subject. states that it can be produced in monkeys either by mite bite or inoculation from a patient, but not in mice or guinea pigs. Infected monkeys show fever but not the skin or genital involvement described by Ricketts as occurring in monkeys inoculated with spotted fever.

Wilson and Chowning thought that rabbits and spermophiles were inoculable with spotted fever. Stiles and Ashburn were unable to produce the disease in them.

Ricketts and King have produced it in monkeys and guinea pigs, and more recently Ricketts appears to have produced it in the horse. 


\section{PROGNOSIS.}

The prognosis, in view of the mortality, is considerably better in tsutsugamushi disease than in spotted fever, and this is particularly true with regard to young subjects. In neither disease, though, can much reliance be placed on mild symptoms during the early days of sickness, for in both it too frequently happens that a patient who for some days has had very moderate fever, a good appetite, no pain and has appeared only slightly or not at all sick, will take a turn for the worse and in a short time be in a very dangerous condition, and later die in spite of the fair promise of the early symptoms. Prognosis, therefore, should be guarded.

In both diseases pregnant women are apt to abort and die. Judging from the cases here reported, we may hope that the differential leucocyte count will prove valuable in estimating the prognosis in given cases of tsutsugamushi disease.

\section{PATHOLOGICAL ANATOMY.}

The knowledge of the conditions found postmortem in both diseases is as yet incomplete, because in the region of flood fever, as in that of spotted fever, there is a sentiment against autopsies and very few of them have been obtained. The only pathological conditions recognized as characteristic of tsutsugamushi disease are the ulcer at the site of the bite, the moderate lymphatic enlargement and the splenic enlargement. Edema of the lungs and hypostatic congestions may be found. The kidneys are swollen and congested and may show acute nephritis.

The findings in tick fever are not greatly different from the above. The characteristic ulcer and the lymphatic enlargement are not present, while the skin lesions are striking and may include large areas of extravasation, or small patches of gangrene. Ricketts' findings of lymphatic enlargement in animals dead of experimental spotted fever indicate that more careful search might reveal such enlargements in human subjects of the disease.

Tsursugamushi Disease.

\section{DIAGNOSIS.}

Tsutsugamushi disease presents points of resemblance to malaria, typhoid, typhus, pneumonia and plague.

The locality and the season at which the disease occurs are, of course, important points in enabling one to differentiate it from those diseases. Examination of the blood for malarial parasites and for the Widal reaction will be of further assistance, as will the absence of most physical signs of pneumonia and the presence of the mite bite, the lymphatic enlargement and the eruption. The character of the epidemic and the presence of plague bacilli in sputum, glands or viscera would differentiate plague. $\mathbf{A}$ mild case of typhus occurring in the endemic region at the proper season would possibly be very hard to differentiate. The darker, more profuse and petechial eruption, the absence of characteristic lymphatic enlargement and of the bite and the contagiousness, should make the diagnosis reasonably certain.

Spotted or tick fever of Montana bears a much closer resemblance to typhus and, in our opinion, can only be differentiated from it by its seasonal and geographical limitations and its lack of contagiousness.

It may also present a great resemblance to cerebrospinal meningitis, from which, in the most nervous cases, it can be differentiated by consideration of season and locality, the more ephemeral nature of the nervous symptoms, the absence of such serious nervous signs as blindness, the occurrence of other and less nervous cases, and, finally, by the autopsy.

Malaria, except recurrences of the disease contracted elsewhere, does not occur in the spotted fever country. Typhoid can be excluded by the blood examination and by the appearance of the rash.

While the wide geographical separation of the two diseases renders it improbable that any one else will be called upon to differentiate tsutsugamushi disease and tick fever of Montana, it is germane to the subject of this paper to summarize here the points of differentiation and that can be done best by means of parallel tables.

\section{SpotTed Fever.}

GEOGRAPHICAL DISTRIBUTION.

Confined to Echigo and Akita provinces in Japan. Contracted on ground that actually has been submerged.

First of March to end of June, usually.

Due to bite of infected larval trombidium.

Five to twelve days usually.
Confined to parts of the Rocky Mountain region.

Contracted on ground that has not been submerged.

SEASON.

End of June to October. ETIOLOGY.

Due to bite of infected Dermacentor orcidentalis. INCUBATION.

One to eight days.

SYMPTOMS, EARLY.

Onset. Usually by chill, followed by headache, malaise. Same. Headache and backache more common.

Pain and swelling of lymphatic glands on first or second Not so. Tick bite, if present, may be inflamed. day leads to discovery of bite.

Bite always present and demonstrable. Shows small Not so. When present it is usually a red mark. black area of necrosis.

Superficial lymphatic glands elsewhere than near wound Not so. become enlarged. 
Temperature $101^{\circ}$ to $103^{\circ} \mathrm{F}$.

Injection of conjunctiva and photophobia are frequent.

Nose and throat normal.

Tongue moist, slightly coated.

Constipation.

Spleen enlarged.
Not so constant.

Same.

Sore throat occasional.

Same.

Often present but not as a rule.

Samie.

Fever to $104^{\circ}$ or $105^{\circ} \mathrm{F}$., continuous.

GYMPTOMS, LATER.

dicrotic.

Exanthem usually fourth to seventh day.

First on face and temples.

Indistinct or absent on thighs and arms.

Macules or papules, dusky.

Usually lasts four to seven days.

Does not become hemorrhagic.

Frequently shows in mouth.

Hyperesthesia common through disease.

Partial deafness frequent.

Tongue and lips may crack and bleed.

Gums spongy, may ooze blood.

Almost always rapid and weak. May be dicrotic. cious.

Perspiration common.

Remission at end of second week.

Ulcers may be long in healing and glands remain"tender.

Usually second to fifth day.

Usually first on wrists and ankles.

Not so.

Macules or petechiae.

Fades more slowly.

Becomes hemorrhagic.

Not so.

Often present.

Less frequent.

Same.

Not so.

Not noted. Skin often dusky or marbled.

No constancy. Most patients dead before that.

No such condition.

\section{COMPLICATIONS}

Parotitis, melena, mania.

Coma, cardiac weakness, pulmonary edema.

Not noted.

Frequent.

MORTALITY.

Thirty per cent. Increases steadily with age.

Seventy-five per cent. No steady increase with age.

PATHOLOGICAL ANATOMY.

Ulcers, lymphadenitis, large spleen, hypostatic conges- No ulcers. Iymphadenitis not noted. Iarge spleen, tions. May be nephritis. hypostatic congestions. May be nephritis.

Not conferred by attack.

\section{PROPHYLAXIS.}

The only prophylactic measure yet put to any general use against either disease is avoidance of the infected regions. This is much easier in the case of flood fever than in that of spotted fever, as the dangerous regions are so much smaller and are so plainly marked off by the very flooding that makes them dangerous and because they are not residence sites. Some of the Japanese investigators are recommending that persons who have to enter the dangerous regions should wear clothing saturated with petroleum. The use of carbolic baths, benzine, oil of peppermint and Balsam of Peru are also advocated. The effectiveness and applicability of these measures remain to be proved. It is stated that cultivation of the soil and the use of human feces as manure will free an infected area from the disease in about three years, if its submersion be meanwhile prevented.

\section{TREATMENT.}

So far as personal observation enables us to form opinions on this subject, it indicates that the treatment in both diseases is divisible into two classes: 1. Expectant, symptomatic. 2. Hopedfor specifics, which are apt to be the result of guesswork or of reasoning from false premises or erroneous observations.
Probably conferred by one attack.

The clinical symptoms of both diseases and the results of practice in clinically similar diseases, such as typhoid and typhus, indicate that each offers a field for a more extended use of hydrotherapy than either has yet received.

\section{CASE HISTORIES OF TSUTSUGAMUSH DISEASE.}

The following are such histories and notes as could be obtained in regard to the cases of tsutsugamushi disease seen by us this year (1907):

CASE I. S. Igarashi. Male, age seventeen years. Farmer.

Family history.-Negative as regards tsutsugamushi disease.

Personal history. - Patient had been in the infected locality at various times and does not know when he was bitten by mites. This is his first attack of the disease.

Present illness. - The disease began on July 24, 1907, with a chill. The next day the patient entered the hospital. At that time the glands of one axilla were enlarged and tender and examination of the region drained by them showed the small ulcers resulting from three bites. There was no skin eruption and the spleen was not demonstrable. The pulse was strong, frequent and regular, appetite decreased and the bowels constipated. Urine was normal. The temperature is shown by Chart I. 


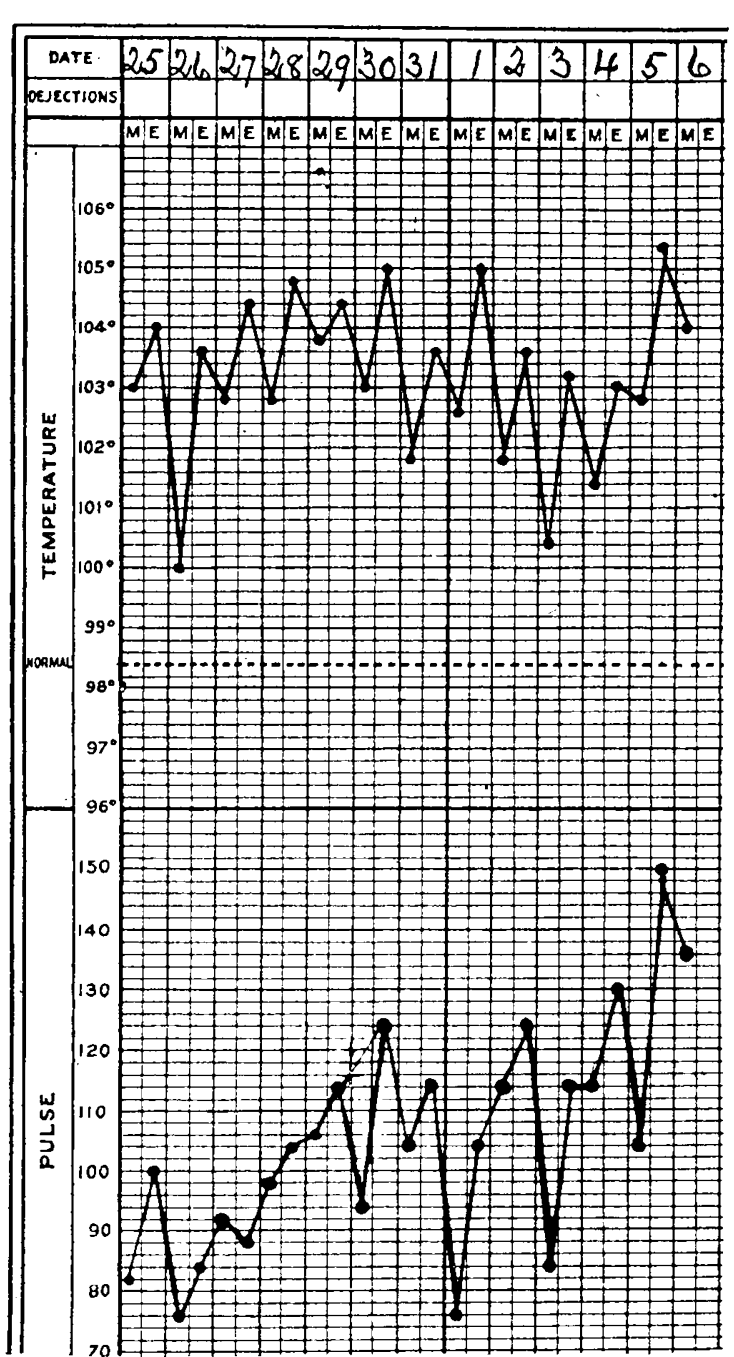

Chart I.

On July 26, an eruption of rose-colored macules appeared on the face. Later it gradually spread over the body and limbs. The diazo reaction was well marked in the urine of the 28th and the pulse was that day dicrotic. The eruption showed on the hard palate and the fauces and some cough was present.

Aug. 1. The present condition is indicated by the foregoing notes, there having been no change.

Aug. 2. The patient is sluggish and stupid. The eruption is still present but is not prominent; the eves are injected and suffused; the spleen is tender but not palpable; respiration is rapid and the pulse feeble The patient sleeps well and has had no delirium.

Aug. 3. The urine contains considerable albumin and numerous coarsely granular casts. The patient sleeps much and perspires frecly, the pulse is 85 , but very weak, the heart sounds feeble. There is no cough; breath sounds everywhere harsh. The eruption still shows on the face and chest but is fading. The eves are much injected. The tongue is dry, white in the center, glazed at the margins, the papilla prominent; gums spongy: spleen tender but not palpable.

Aug. 4. The general appearance and condition are about as vesterday. The gums are very spongy and are bleeding. Cough is present and produces a scant, tenacious sputum, much discolored with blood from the gums. Respiration is rapid and somewhat irregular, the breath sounds harsh. The pulse is rapid, irregun? and of low tension, the first heart sound feeble. There is slight edema of the feet. 'The eruption remaining on the face is yapular and the apex of each yapule shows a minute scab; the conjunctiva are much in jected.

Aug. 7. We left on the 5th to visit another infected region and on our return this morning we learn that the patient became progressively worse and died on the morning of Aug. 6, with high temperature and edema of the lungs. Autopsy was not obtainable.

Case II. I. Hasigawa. Female, age thirteen years.

Family history negative as regards this disease.

Personal history. - The patient has been in the tsutsugamushi infected region and was bitten by a red mite on July 17, 1907. This is her first attack of the disease.

Present illness. - On July 22, she had a chill and next day entered the hospital. At that time she had fever, a flushed face, weak and rapid pulse, poor appetite and diarrhea, the last a very unusual symptom. The left femoral glands were enlarged, painful and tender and just below them was the small ulcer resulting from the mite bite. It was surrounded by a slightly infiltrated pink border.

On the 27th the spleen was demonstrably enlarged and the urine gave the diazo reaction. It contained no albumin. The patient was delirious at times and was extremely hypersensitive. The temperature is shown by Chart II.

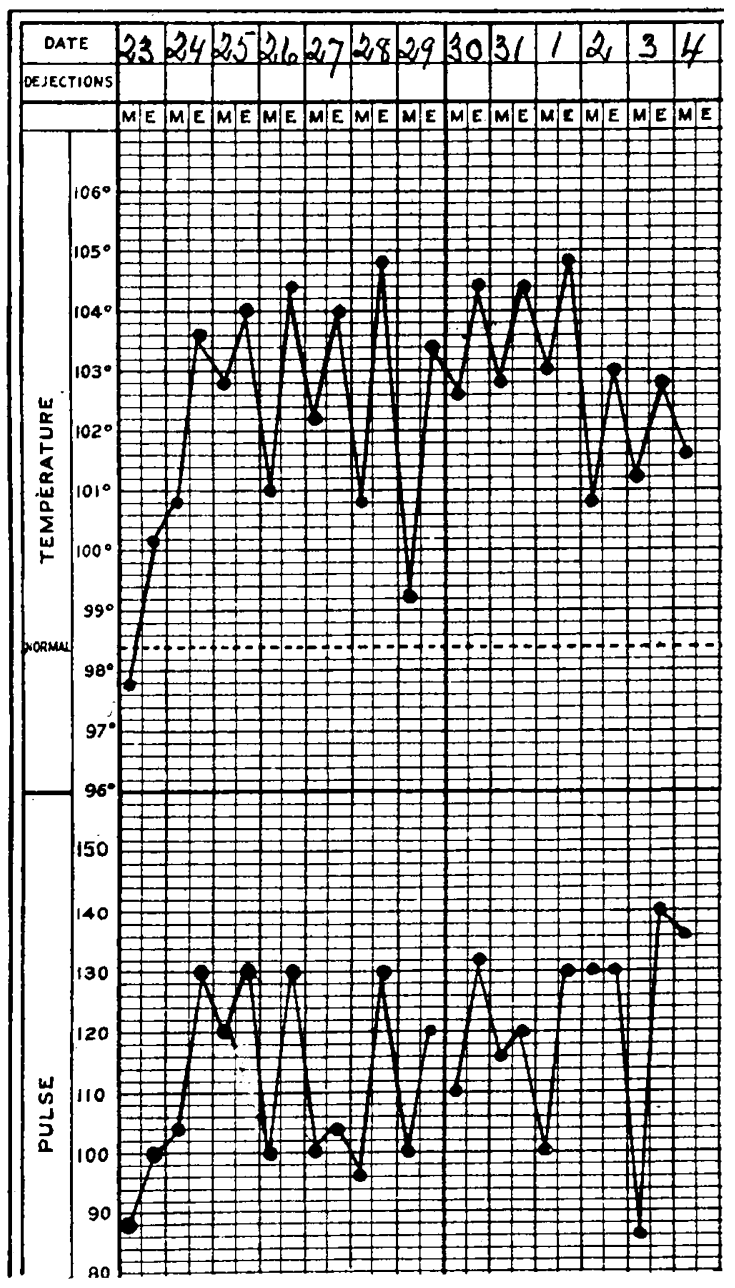

Chart II. 
Aug. 1. Eruption appeared this morning for the first time, showing on the face. It is rubeolar in appearance, but scanty. Diarrhea has ceased under treatment. The pulse is growing weaker. Cough is present but unproductive of aught save pain; breath sounds every where harsh.

Aug. 2. The patient slept well last night and is not delirious. The pulse is rapid and fecble; cough persists and causes abdominal pain; hyperesthesia is very marked and pain causes the patient to moan a great deal. The abdomen is particularly painful and tender but is not distended or rigid. The bowels are loose. There is a dusky, faint, scattered, macular eruption on the face, arms and legs. Tenacious mucus in the throat excites cough and nausea.

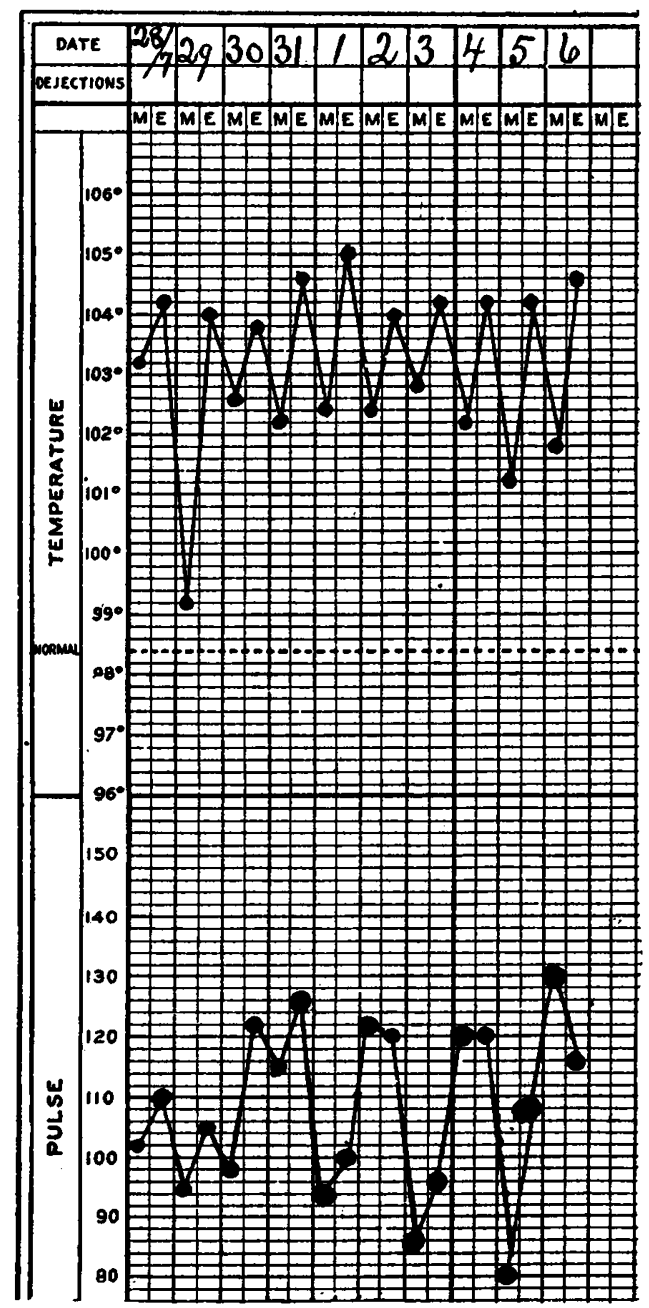

Chart III.

Aug. 3. Face: dusky, cyes congested, eruption less distinct; t tongue dry and glazed and its papillæ prominent. Hyperesthesia, abdominal pain and diarrhea persist. Patient slept poorly last night and is delirious. Respiration rapid and moaning; breath sounds harsh; cough less severe and distressing. Pulse recorded as 85 but during examination it was 140 and weak. Heart sounds rapid and weak but clear.

Aug. 4. Patient died at 6.00 A.M., to-day.

Delirium had ceased, but diarrhea persisted and the heart became rapid and weaker until death occurred. Autopsy was not obtainable.
CASE III. H. Itagake. Male, age fourteen years.

Family history negative as regards this disease.

Personal history. - The patient has visited the infected regions and was bitten by a mite on July 19. This is his first attack of tsutsugamushi disease.

Present illness. - The disease began with a slight chill on July 27 , since that time the patient has had moderate fever and enlargement of the lymphatic glands, particularly of the right axilla, but has felt comfortable and has not appeared very sick. The temperature is shown by Chart III.

Aug. 1. Patient has had no symptoms except the fever, slight headache and constipation and does not look or feel very ill. There is no eruption and the spleen is not demonstrably enlarged. The right axillary glands are swollen and tender and the skin of the same axilla shows a small ulccr with pinkish, slightly indurated and tender margins.

Aug. 2. Face clear and bright. No cruption present and the patient looks well. The tongue is white, slightly dry and tooth-marked. The pulse is of good strength.

Aug. 3. The face is flushed, the eves injected, a faint eruption present. The patient looks sicker than he did yesterday but does not complain. The tongue is moist and has a white coating, the spleen somewhat enlarged and tender, but not palpable. There is no cough but the breath sounds are harsh, especially at the apices of the lungs. The urine shows a trace of albumin and very numerous, coarsely granular casts and small round epithelium, but no blood. Fxamination of the feces shows ascaris eggs but is otherwise negative.

Aug. 4. The skin is hot, the face flushed, eyes injected, expression sommolent. The tongue is somewhat dry, red at the margins and has a thick, yellowish white, central coat. The gums are normal. Cough is present but there is no expectoration. Respiration is rapid and regular, the breath sounds harsh. The pulse is rapid, compressible and regular; the first sound of the heart roughened over the base and apex.

Aug. 7. On our return to the hospital we learned that the patient had grown worse and had become very nervous and that he had left the hospital on August 6.

His subsequent history is unknown to us.

Casf IV. S. Asai. Male, age seventeen years.

Family history negative as regards this disease.

Personal history. - Patient has been in the infected regions but was not aware that he had been bitten by nites. On July 27, he felt listless and feverish and on the 29th, he came to the hospital. At that time he had fever (see Chart IV), his face was flushed and he complained of headache and pain in the pharynx. The lymphatic glands in the left axilla were swollen and painful and careful examination revealed the presence of two small ulcers, one in the left axilla and one back of the hair line of the left frontal region.

Aug. 1. Condition as at time of admission. No eruption has shown and the patient looks and feels well. Spleen not palpable or tender. Slight systolic roughening is noticed over base and apex of the heart. There is slight enlargement of the superficial lymphatic glands, more marked in the left axilla. Physical examination is otherwise negative.

Aug. 2. The patient looks and feels well, has a good appetite, no pain, no eruption and sleeps well. The ulcer on the head has healed.

Aug. 3. The patient looks and feels well. The systolic roughening persists unchanged.

Aug. 4. Discharged from hospital, recovered.

Case V. T. Suzuki. Male, farmer. Age, forty-four years.

1.: Family history. - One son had this disease two years ago. 
Personal history. - The patient had an attack of tsutsugamushi disease at the age of seventeen years and a second attack at the age of twenty-five years. Lately he has visited the infected region but he does not know

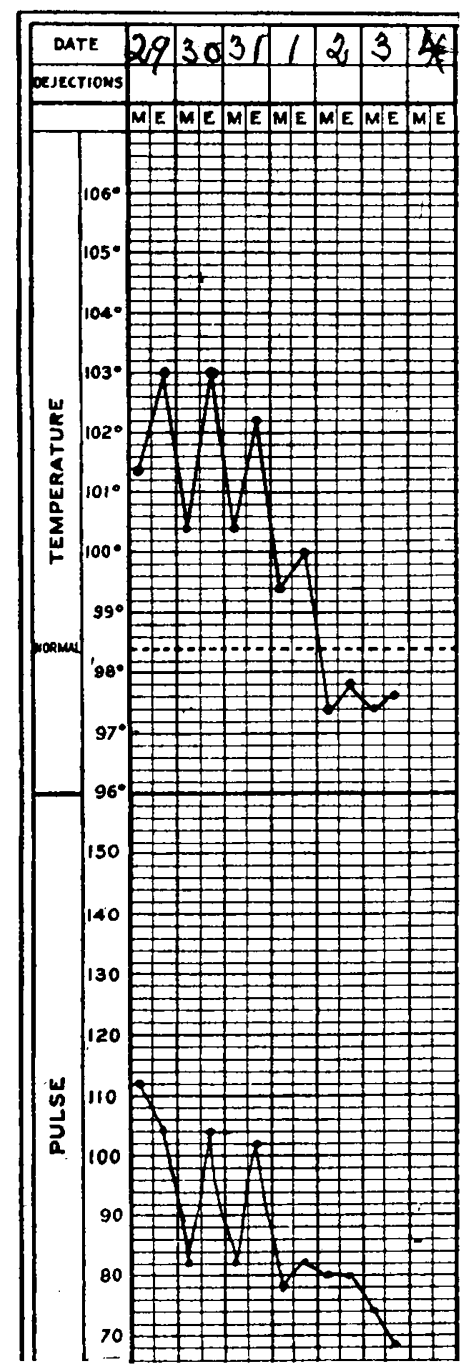

Chat'T IV.

when he was bitten by a mite. On July 28 , he began to suffer from malaise and he came to the hospital on the 30th. At that time he had fever (see Chart V) and the right inguinal glands were enlarged, painful and tender. At the right margin of the umbilicus was a very small ulcer with red, puffy edges and covered with a thin crust. There were no other symptoms.

Aug. 1. Enlargement of the epitrochlear glands is noticed but they are not tender. Patient feels well and looks so. Physical examination is negative.

Aug. 2. There has been no change since yesterday. The spleen is not demonstrably enlarged, the tongue is moist, clean at the edges and shows a white, central coat; there is no eruption, the bowels are sluggish.

Aug. 3. There is no change in the general appearance or condition.

Aug. 4. There is no marked change. The patient eats and sleeps well, and, except for his fever, the ulcer at the umbilicus and the lymphatic enlargement, papillæ project red and prominent. The eyes are not appears to be well. The bowels are moving naturally. red or inflamed. Scattered over the face is a slight

Aug. 5. The patient to-day insisted on leaving the eruption, which first appeared last night. It is most hospital, and did so notwithstanding the persistence of ever and the remonstrances of his attendants.

The subsequent history of the case is unknown to us.

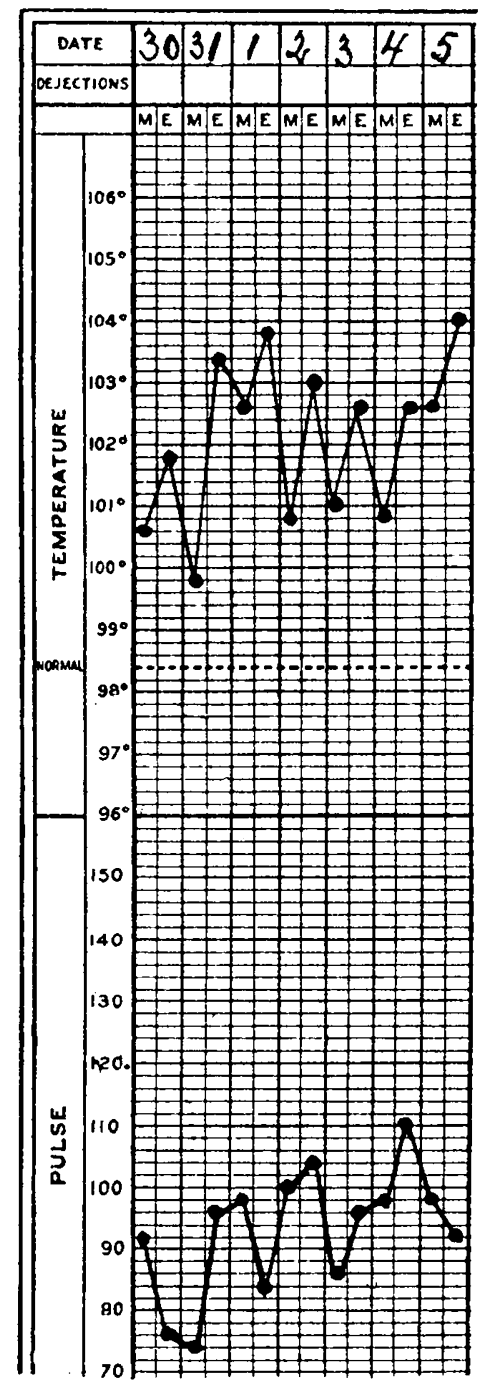

Chart V.

Case VI. Male. Age, eight ycars.

Family history. - The patient's mother had tsutsugamushi disease twelve and his father two years ago, both recovering. An employee living in the same house also had it at one time but the date is unknown.

Personal history. - The patient has at times been fishing in the infected region but does not know of having received any bite from a red mite. On July 30 , he had a chill and since that time has had fever.

Aug. 2. The patient was this morning brought to hospital for the first time by his father.

He has a temperature of $103.2^{\circ} \mathrm{F}$. and severe headache. The post-auricular and upper cervical glands of the left side are enlarged, tender and painful. Examination shows a mite bite just to the left of the sagittal suture at the vertex. It is a small, brown circle of necrotic skin, about $2 \mathrm{~mm}$. in diameter. The brown, necrotic tissue is loose at the margins but most intimately adherent by its under surface to the sound scalp. 
prominent on the cheeks and consists of faint, dusky macules, 2 to $5 \mathrm{~mm}$. in diameter, which fade on pressure and return very promptly when the pressure is relieved. The spots present the slightest perceptible degree of elevation. There is no eruption in the mouth or throat. The spleen is enlarged, the appetite poor, the bowels constipated; there is no cough and the heart and lungs are normal.

Removal of the necrotic area of the bite by means of forceps and scissors leaves a small ulcer with steep margins and a whitish or grayish lining, the appearance of which is said to be very characteristic.

Aug. 7. The patient did not enter the hospital and we have seen him but the one time. We are told that his fever is high and his condition serious.

The subsequent history is unknown to us.

Case VII. Sakuma. Male, farmer, age twenty years.

Family history is negative as regards tsutsugamush disease.

Personal history. - The patient has not had this disease previously. On July 27 he was bitten by a red mite. On Aug. 3 he was taken sick with fever and a feeling of uneasiness. He continued feverish but had no great discomfort, nor any marked symptoms, and came to the hospital on Aug. 5. The maximum temperature that day was $104^{\circ} \mathrm{F}$., the highest pulse rate 94 . On the sixth the highest temperature was $103.2^{\circ} \mathrm{F}$, the highest pulse rate 107 .

Aug. 7. We saw the patient for the first time this morning. He has a temperature of $102.2^{\circ} \mathrm{F}$. and a good pulse of 95 . There is slight enlargement of the superficial lymphatic glands, most marked in the left axilla, where they are also tender. The bite is located in the left axilla and is an ulcer with a mass of black, necrotic tissue still attached to its central part. It is larger than usual, being about $1 \mathrm{~cm}$. by $0.5 \mathrm{~cm}$. The conjunctivæ are congested, the tongue moist and white and an eruption is present this morning for the first time. This is most marked on the right cheek and consists of six dusky, very slightly elevated papules which fade on pressure. The bowels are regular and the patient has neither cough nor pain. He sleeps and.eats well but his expression is somewhat dull and listless. The spleen is slightly enlarged but neither tender nor palpable. The examination of heart and lungs is negative. We did not see this patient again and know nothing of his subsequent history.

XVI. CONCLUSION AS TO THE NONIDENTITY OF THE TWO DISEASES.

We think that a consideration of the facts concerning the two diseases, as at present known and set forth above, justifies the opinion that they are separate and distinct disease entities. They present many points of resemblance but not enough of them to overbalance those of difference.

XVII. DOES TSUTSUgamushi DISEASE OCCUR IN THE PHILIPPINE ISLANDS?

The ready answer which the large majority of medical men in the Islands would give to the above question would be in the negative and it is probable that that is correct. Nevertheless, certain cases that are seen should lead to a more complete investigation of the subject. There occur in these islands a great many cases and probably several kinds of anomalous fevers and in our report for the quarter ending June 30, 1906, we made passing reference to two cases seen by one of us at Camp Connell, Samar, in the preceding February.

We are in possession of the temperature charts and the notes made on those cases by First Lieut. Earl H. Bruns, Assistant Surgeon U. S. Army. As these cases bear considerable resemblance to those of tsutsugamushi disease, it seems advisable to refer to them again and more at length.

Refore relating the cases it is well to mention the climatic conditions under which they occurred. Camp Connell is located on the west coast of Samar and lies but a few feet above sea level. At one side of it is a low, flat stretch of land that was formerly a swamp, but it has been drained and made into a target range. In time of very heavy rains water still covers the range and it may be submerged for two or three days at a time, or such was, at any rate, the condition in 1905 and 1906. The ordinary annual rainfall at the post is about 110 to 120 inches, and almost all of the precipitation occurs between the first of June and the first of January. During January the target range is apt to become dry and hard. In 1905 the post suffered from drought, which began in January and was not fully relieved until late in May. In 1906 there was again very little or no rain in January and a repetition of the condition of the previous year was feared at the time that these cases occurred. The condition of the target range in December, January and February is somewhat similar to that of the tsutsugamushi infected regions in Japan in June, July and August. One of us (Ashburn) happened to be at Camp Connell investigating the question of water supply in February, 1906, and was asked to see the two cases to be quoted, because of their resemblance to the spotted fever of Montana. The notes to follow were made by Lieutenant Bruns eighteen months before we saw any tsutsugamushi disease or considered the possible relationship between the two infections.

Case $A$. D. L. D. Age twenty-nine. Private, Co. M, 21st Infantry.

Family history. - Negative.

Personal history. - The patient has had the usual diseases of childhood, pneumonia at nine years and at fourteen years, dysentery in 1901, malaria in 1901, gonorrhea and chancroids in 1905.

Presert illness. - Jan. 29, 1906. For the past six days he has had headache and pain in the back and has been feverish and constipated, but has had no chill. He was admitted to the hospital this morning with the following symptoms and signs: headache, pain over the kidneys, constipation, slight pain in right iliac fossa, slight dry cough; heart, lungs, liver and spleen normal. There is an eruption of flat, rose-colored, irregular macules scattered over the chest, abdomen and legs and about the anus. General glandular enlargement is present, the right femoral glands being also painful and tender.

(For the temperature see Chart A.)

Jan. 30. No malarial parasites in blood; leucocyte count 5,400 ; urine normal.

Jan. 31. Glands in right femoral region more enlarged, tender and painful. There are headache and slight abdominal pain.

Feb. 2. Muttering dilirium, nervous twitching and 
subsultus are present this morning. The skin is mottled and the eruption increased on chest, abdomen, neck, face, legs and about the anus. Tongue coated and dry, pulse dicrotic. Femoral glands smaller.

Feb. 3. Breathing is thoracic and shallow; face flushed; femoral glands painful; eruption more dusky. The pulse is rapid and irregular.

Feb. 4. No change. Blood shows no malarial parasites; leucocyte count 4,300 .

Feb. 6. The patient feels better this morning; the pulse is of good tension, the eruption fading.

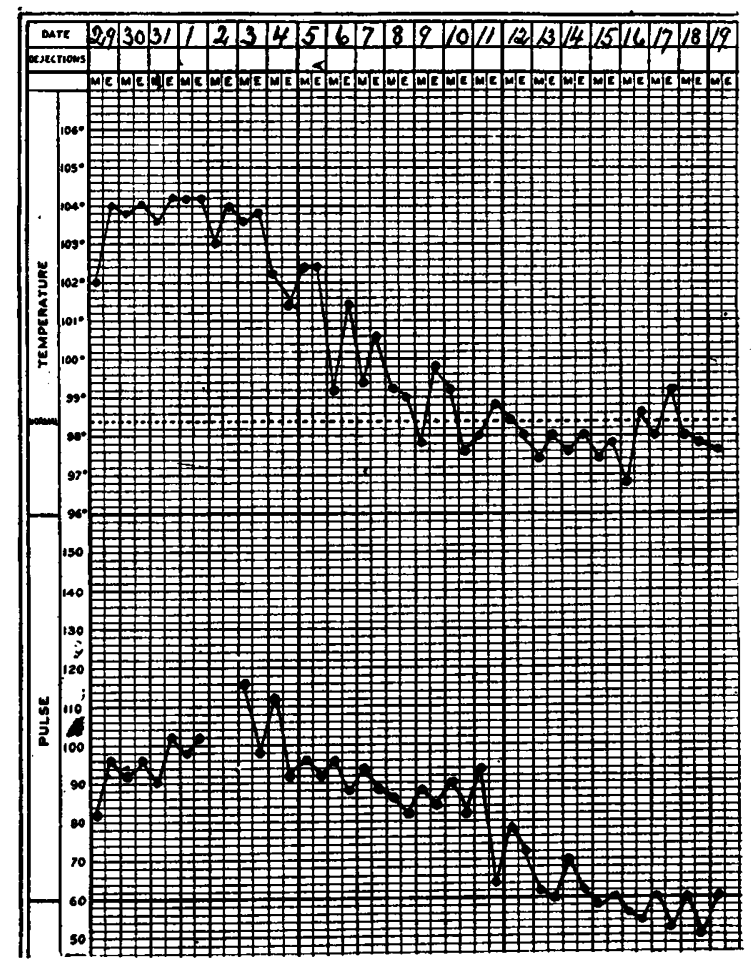

Chart A.

Feb. 9. Improved. Patient looks brighter and feels very well. His mental condition is peculiar, not normal.

Feb. 10. Delirious all night and to-day. Fare flushed; pulse remains fairly strong.

Feb. 11. Improved, quiet, no pain.

Feb. 13. Improved, hungry. The pulse is good and the rash disappearing. Urine normal.

Feb. 16. The patient has improved. He has no pain, the pulse is strong, the eruption and glandular enlargement have disappeared.

Feb. 19. The Widal reaction is negative after one hour.

CASE B. H. D. P. Age thirty-four, teamster.

Family history. - Negative.

Personal history. - The patient has had diseases of childhood, "typhoid-malaria" in 1894, dysentery in 1903. There is no history of syphilis or gonorrhea.

Present illness. - Feb. 2, 1906. The patient has felt badly for five days and has had headache, pain in the back and limbs and in abdomen and the appetite has been poor. There was no chill and but slight cough. Two days ago he noticed enlarged glands in the right axilla and right groin. Yesterday he had diarrhea. He was admitted to hospital to-day suffering from fever, pain in the head, back, legs, anus and abdomen, enlarged and painful lymphatic glands in the right axilla and groin and diarrhea.
Physical examination: The heart is normal; dry rales are heard over the upper lobes of hoth lungs. The abdomen is tender around the umbilicus, the spleen enlarged. A rose-colored, irregular, macular rash shows on the head, trunk and limbs. There is a general enlargement of the superficial lymphatic glands, more marked in the right axilla and groin. The tongue is moist and has a white, central coat and red edges. No malarial parasites found in the blood.

(For the temperature see Chart 13.)

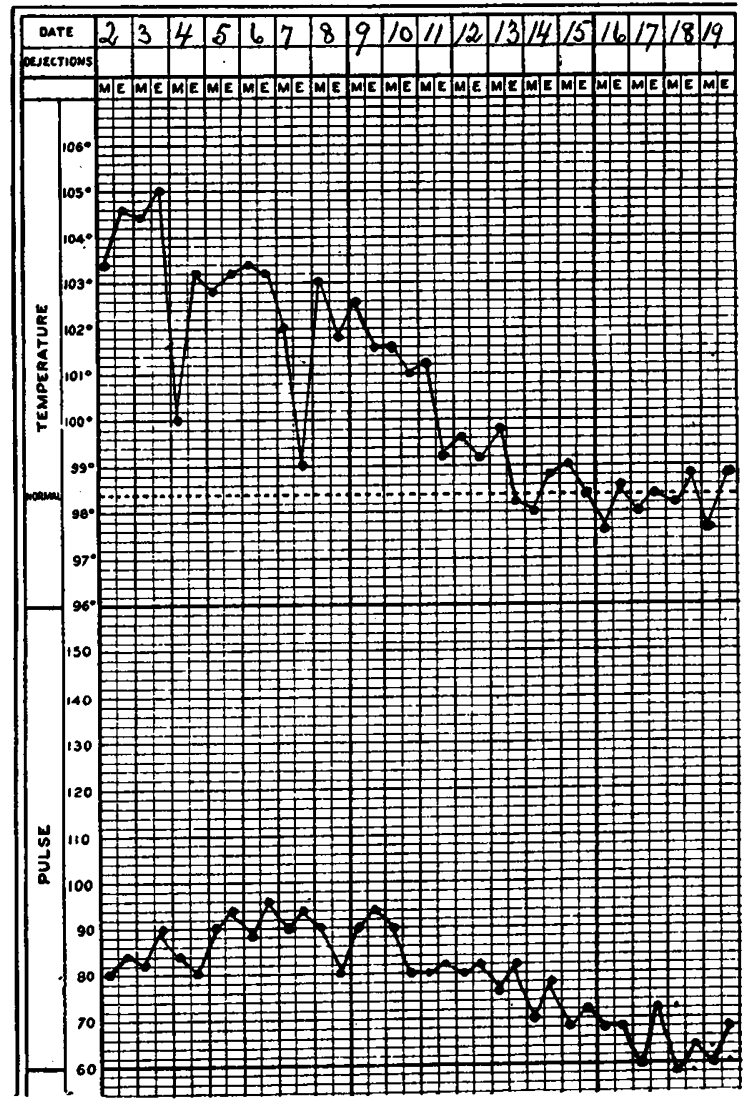

Chart B.

Feb. 3. No malarial parasites. The patient is dull, the face flushed, the axillary and inguinal glands painful.

Feb. 4. There is no change. Leucocyte courit 3,200 no malarial parasites.

Feb. 5. Patient appears better this morning. The pulse is of good tension, the eruption fading. There was a marked chill after a plunge bath.

Feb. 6. The eruption is fading, the pulse is good, the tongue dark and dry. No malarial parasites in the blood. A differential count of white cells shows: small lymphocytes 20 , large lymphocytes 8 , polymorphonuclears 60 , eosinophiles 2 , transitionals and large mononuclears $4 \%$.

Feb. 9. Still improving. A gland was removed from the right groin for examination.

Feb. 10. Improving. Face flushed, eyes injected, mouth dry and the tongue shows a yellowish coat. The pulse is of good tension, the eruption confluent and fading. No malarial parasites in the blood.

Feb. 12. Patient is still improving. He sleeps well. Bacteriological examination of the excised gland was negative. 
Feb. 13. The patient is hungry, the eruption has disappeared, the glandular enlargement is less marked and the urine is normal.

Feb. 19: Fatient is still improving. Widal reaction was negative after one hour. No malarial parasites found in the blood.

Lieutenant Bruns made daily notes on these cases but when there was no change in the condition or no new examination mentioned the remarks have been omitted.

Both patients received cold baths during the progress of the disease and the charts are probably modified by them. While the notes do not indicate it, such is probably the explanation of the two marked drops of temperature shown by Chart B. A satisfactory diagnosis was never made on either case, though both were reported as typhoid fever.

We do not maintain that these cases were tsutsugamushi disease, but they certainly present enough points of resemblance to it to make it worth while for medical men in the Philippines to keep the matter in mind should they have the opportunity of investigating similar cases.

\section{ACKNOWLEDGMENT.}

We desire to express our thanks to those assisting us in this study and particularly to Professor Miyajima and his fellows from the Imperial Institute for Researches of Infectious Diseases, to whom we are indebted for the opportunity to see what we did of tsutsugamushi disease, and for such knowledge as we have of the articles published on it in Japanese, as well as for the information they gave us concerning their own work, and to Lieutenant Bruns, for his notes on the Camp Connell cases.

BIBLIOGRAPHY.

Tsutsugamushi Disease.

Bälz, E., and Kawakami: Die Japanische Fluss-oder Ueberschwemmungsfieber. Virchow's Arch., lxxviii, 1879, p. 373.

Nachtrag zu dem Aufsatz über Flussfieber. Ibid., p. 528.

Ogata, M.: Vorlaufige Mitteilung über die Aetiologie der Tsutsugamushi (Kedani) Krankheit. Deut. med. Wochenschr., 1906, no $46, p, 1868$.

Palm, Th. A.: Some acrount of a disease called Shima Mushi or Island Insect Disease by the Natives of Japan. Edin. Med. Jour. Aug., 1878, p. 128 .

Tanaka, Keisuke: Ueber Aetiologie und Pathogenese der Kedan Krankheit. Centralbl. für Bakt., xxvi, 1899, Nos. 14, 15, p. 432 .

Ueber meine Japanischer Kedani Krankheit. Ibid., xlii, No. 2.

There is a quite extensive Japanese bibliography on this disease which is not cited as it was not accessible to us and would not be to most of our readers.

\section{Spotted Fever of Montana.}

Anderson, J. F.: Spotted Fever (tick fever) of the Rocky Mountains: A New Disease. Bull. 14 Hyg. Lab. U. S. Pub. Health and tains: A New Disease. Bull. 14 H

Mar.-Hosp. Serv . Washington, 1903.
Ashburn, P. M.: Piroplasmosis Hominis (?) - Spotted Fever of Ashburn, P. M.: Piroplasmosis Homi
Montana. Lancet-Clinic, April 22, 1905.

A Suggestion as to the Treatment of the Spotted Fever of Montana. Lancet-Clinic, May 20, 1905.

tana. Lancet-Clinic, May 20, 1905.
Craig, C. F.: The Relation of the so-called " Piroplasma Hominis " and Certain Degenerative Changes in the Erythrocytes. Am. Med. and Certain Degenera

Kon, viii, w. 1016. Spotted Fever by Means of the Tick: Preliminary note. Pub. 863.

Ricketts, H. T.: The study of "Rocky Mountain Spotted Fever" (Tick Fever?) by Means of Animal Inoculations. A prelin

muncation. Jour. Am. Med. Asso., 1906, xlvil, p. 33 . of the Wood Tick (Dermacentor occidentalis). Ibid., p. 358.

Further Observations on Rocky Mountain Spotted Fever and Dermacentor Occidentalis. Ibid., 1067.

Observations on the Virus and Means of Transmission of Rocky Mountain Spotted Fever. Jour. Infect. Dis., 1907, iv, p. 141.

The Rôle of the Wood Tick (Dermacentor occidentalis) in Rocky Mountain Spotted Fever and the Susceptibility of Local Animals to this Disease. A preliminary report. Jour. Am. Med. Asso., 1907, this Disease. A preliminary report. Jour. Am. Med. Asso., 1907,
Slix, 24.
Stiles, Chas. Wardell: A Zoölogical Investigation into the Cause
Transmission and Source of Rocky Mountain " Spotted Fever." Bulletin 20, Hygienic Laboratory, Pub. Health and Mar.-Hosp. Serv, Washington, 1905 .

Wilson, Louis B., and Chowning, Wm. M.: The so-called " Spotted Fever " of the Rocky Mountains. A preliminary report to the Montana State Board of Health. Jour. Am. Med. Asso., 1902, xxxix, p. 131

Report on the Investigation of So-called "Spotted Fever." First Report of the Montana State Board of Health, Helena, Mont., 1903. Studies in Pyroplasmosis Hominis. ("Spotted Fever " or "Tick Fever" of the Rocky Mountains.) Jour. Infect. Dis., 1904, i, p. 31

\section{A STUDY OF THE VALUE OF MEASUREMENTS OF CHEST EXPANSION.}

$$
\begin{aligned}
& \text { BY HARRY W. GOODALL, M.D., BOSTON, } \\
& \text { JND } \\
& \text { J. LYMAN BELKNAP, M.D., BOSTON. }
\end{aligned}
$$

Opinions differ as to the value of the measure of chest expansion in health and in early pulmonary disease.

Cabot says the measure yields very little information of practical value and at present is very little used. DaCosta says we are able to estimate the amount of air received into the lungs, but the results are not, on the whole, reliable. Sahli and Butler attach considerable importance to the measurement, and Anders says with the growirg adoption of diagnostic methods of precision this most important one, mensuration, deserves at once increasing scientific study and practical application.

In the routine examination of supposedly healthy individuals by Medical Examiners for Government service, insurance companies and the like, where standard tables of normal individuals are used for comparison, chest expansion receives very serious consideration, as, for example, in the United States Army and Navy an expansion of less than two or two and one half inches may be sufficient cause to reject the individual. Many insurance companies do not consider an applicant with an expansion of less than two inches a good risk.

The following study of chest movements shows that, instead of a precise, simple diagnostic method, we have to do with one capable of considerable error in technic and interpretation and that one can undoubtedly determine the molility of the chest walls, but that this measurement does not necessarily assist us in determining the true lung expansion.

This thoracic enlargement in normal inspiration is brought about in two ways, - the descent of the diaphragm and the elevation of the ribs.

In the male the diaphragm is the chief respiratory agent and even in the female plays such an important part that it is not to be neglected. In its descent the abdominal organs are pushed downward, as is evidenced by the projection of the abdominal walls, and result in an increased vertical diameter of the thoracic cavity. The groups of muscles which are brought into play in elevating the ribs are chiefly responsible for the difference in the anteroposterior and transverse diameter of the chest.

Inspiration being a voluntary act it is at once 